\title{
Intraspecific Relationships and Variation of Two Lefua Species (Balitoridae, Cypriniformes) in the Tokai Region, Honshu, Japan
}

\author{
Jun-Ichi Miyazaki' ${ }^{1}$, Seiya Hida ${ }^{1}$, Takurou Ozaki ${ }^{1}$, Yuichirou Tabata ${ }^{1}$, Misaki Iwata ${ }^{1}$, \\ Masashi Nakazawa', Youki Fukasawa ${ }^{2}$, Tomonari Asaka ${ }^{3}$ \\ ${ }^{1}$ Faculty of Education and Human Sciences, University of Yamanashi, Kofu, Japan \\ ${ }^{2}$ Department of Education, Graduate School of Medical and Engineering, University of Yamanashi, Kofu, Japan \\ ${ }^{3}$ Mikawa Freshwater Life Network, Toyokawa, Japan \\ Email: miyazaki@yamanashi.ac.jp
}

How to cite this paper: Miyazaki, J.-I., Hida, S., Ozaki, T., Tabata, Y., Iwata, M., Nakazawa, M., Fukasawa, Y. and Asaka, T. (2017) Intraspecific Relationships and Variation of Two Lefua Species (Balitoridae, Cypriniformes) in the Tokai Region, Honshu, Japan. Journal of Water Resource and Protection, 9, 238-253.

https://doi.org/10.4236/jwarp.2017.92016

Received: January 10, 2017

Accepted: February 12, 2017

Published: February 15, 2017

Copyright $\odot 2017$ by authors and Scientific Research Publishing Inc. This work is licensed under the Creative Commons Attribution International License (CC BY 4.0).

http://creativecommons.org/licenses/by/4.0/

\begin{abstract}
Two species Lefua echigonia and Lefua sp. 2 of the eight-barbel loach inhabit the Tokai region of Honshu, Japan. We determined sequences of the mitochondrial D-loop region to elucidate intraspecific phylogenetic relationships and variation in these two species. Lefua sp. 2 represented high intraspecific genetic similarity and complicated haplotype network, but three assemblages were recognized, including specimens mainly from Yahagi, Toyo, and Tenryu River systems, respectively, and named Groups 1 to 3. Divergence of Group 1 from the others was marginally supported, but Group 2 was paraphyletic to Group 3, suggesting the existence of two populations, i.e. Yahagi River population and Toyo-Tenryu River population. Lefua echigonia also represented high intraspecific genetic similarity, and two assemblages with slight genetic differentiation were discernible, including specimens from Shizuoka and southeastern Aichi prefectures and those from northwestern Aichi, Gifu, and Mie prefectures, respectively, and named Groups A and B. Star-like relationships of haplotypes suggested the dispersal origin located in eastern Aichi prefecture. The two species are threatened to extinction and thus we proposed evolutionary significant units for conservation.
\end{abstract}

\section{Keywords}

Population, Phylogeography, Mitochondrial D-Loop Region, Conservation, River Capturing 


\section{Introduction}

Eight-barbel loaches belonging to the genus Lefua (Balitoridae, Cypriniformes) are primary freshwater fish less than $10 \mathrm{~cm}$ in total length. The evolutionary process in Lefua forms part of the evolutionary history of Japanese and East Asian freshwater fishes. Four species have been formally described. Lefua nikkonis (Jordan et Fowler, 1903) is endemic to Hokkaido, Japan, L. echigonia Jordan et Richardson, 1907 inhabits Tohoku to Kinki districts in Honshu, Japan, and $L$. costata (Kessler, 1876) is distributed widely in East Asia including Korea, China, and Russia, but has been introduced to restricted areas in Honshu, Japan [1]. Lefua pleskei (Herzenstein, 1887) is distributed in eastern Russia [2]. Another species, Lefua sp. was separated from L. echigonia based on morphological traits with a greater distance between the dorsal and ventral fins, longer snout length, lower body height, and narrower body width of Lefua sp. than L. echigonia [3] [4], and on ecological traits with habitats of relatively fast-flowing mountain streams with gravelly beds of Lefua sp. contrasting with habitats of relatively slow-flowing streams with muddy beds in marshlands, spring water, rice paddy irrigation channels, and the backwaters of floodplains of L. echigonia [5]. Lefua sp. is waiting for a formal scientific description. This species is distributed in western Japan including Kinki, Hokuriku, and Chugoku districts in Honshu and also in Shikoku. Additionally, we suggested recently that Lefua loach occurring locally in Aichi and Shizuoka prefectures of the Tokai region in Honshu, Japan is the sixth possible species [6] [7]. Although the loach had been identified as Lefua sp. on morphological and ecological grounds as above, our phylogenetic study by mitochondrial DNA (mtDNA) and nuclear DNA (nDNA) sequencing showed that the loach in the Tokai region comprised a monophyletic group and was more closely related to L. echigonia than to Lefua sp. In our previous study, we designated it the $L$. sp. Tokai population, and thereafter Lefua sp. in western Japan was classified as Lefua sp. 1 and the loach in the Tokai region as Lefua sp. 2 in the Red List issued by the Japanese Ministry of the Environment in 2014 (see also [8]). According to the classification, we herein designate the loach in the Tokai region as Lefua sp. 2. Some studies showed embryological differences in Lefua loaches [9] [10] [11] [12]. However, we cannot perform comparative embryology among the above six species and among intraspecific populations of each species, because those studies have been done using only limited samples of two species, Lefua sp. 1 and L. echigonia.

Although the taxonomic status of Lefua sp. 2 remains to be specified, it has a unique evolutionary background clearly [6]. We suggested parallel morphological evolution between Lefua sp. 1 and Lefua sp. 2 [7]. Although their distributions are disjunct, both species occur in relatively fast-flowing mountain streams with gravelly beds and generally have more slender bodies for adapting to fastflowing streams than L. echigonia. The slender bodies allow them to avoid fast flowing water through exploitation of spaces within the gravel bed of streams. Lefua sp. 2 and L. echigonia inhabit the Tokai region. Complex geological events 
in their distribution range are likely associated with the evolutionary process. Upliftment in the whole range might have forced ancestors of Lefua sp. 2 to adapt to fast-flowing mountain brooks [7]. Later L. echigonia invaded the Tokai region during erosion of the western flanking zone (Ryoke metamorphic belt) of the Median Tectonic Line (MTL). At present, Lefua sp. 2 preferentially inhabits the eastern flanking zone (Sanbagawa metamorphic belt) of MLT and the zone of uplifted volcanic and marine deposit. The Ryoke metamorphic belt tends to be strongly eroded, producing relatively flat terrain suitable for development of L. echigonia habitat. This is not the case in the Sanbagawa metamorphic belt of a different rock composition.

Because of its extinction risk and unique evolutionary background, Lefua sp. 2 was registered as endangered species in the Red List as well as L. echigonia, Lefua sp. 1, and L. nikkonis [4] [13] [14]. These Lefua loaches have been severely threatened by habitat destruction due to human activities. We demonstrated that L. echigonia comprised genetically seven intraspecific populations (Hokuriku, Tohoku, Yamagata, North-Kanto, South-Kanto, Kinki, and Tokai) and Lefua sp. 1 comprised two intraspecific populations (Kii-Shikoku and Sanyo) [7] [15]. These populations occur in regions that are geographically well separated by mountain ranges and highlands [1] [16]. The populations should be considered evolutionary significant units (ESUs, as defined by Moritz [17]) for the protection of the endangered loaches [1]. However, intraspecific phylogenetic relationships and variation in Lefua sp. 2 have not been investigated thoroughly. Elucidation of cryptic ESUs is crucial for the protection of this unique loach.

In the present study, we demonstrate intraspecific phylogenetic relationships and variation in Lefua sp. 2 and L. echigonia (Tokai population) by sequencing the mitochondrial D-loop region. We present fundamental information for the protection of these endangered species, and discuss their evolutionary history in the Tokai region.

\section{Materials and Methods}

\subsection{Materials}

Collecting localities of Lefua sp. 2 (83 specimens) and L. echigonia (40 specimens) are shown in Figure 1 and information on all samples including outgroup specimens is listed in Table 1. Since both species was registered as endangered species in the Red List, we used large circles on Figure 1 to conceal detailed information of habitats for the conservation of the two endangered species. Specimens of Lefua sp. 1 obtained from Hidaka (Sanyo population) and L. echigonia obtained from Ouchi (Hokuriku population) were used as the outgroup for the Lefua sp. 2 phylogeny. Those of L. echigonia obtained from Aogaki (Kinki population) and Ouchi were used as the outgroup for the L. echigonia phylogeny in the Tokai region. Lefua sp. 2 and L. echigonia are sympatric in Sanagawa, Aichi Prefecture (sample Nos. 69 and 111), and occur in the close vicinity in Kosai, Shizuoka Prefecture (sample Nos. 80 and 118). 
Table 1. Sample list.

\begin{tabular}{|c|c|c|c|c|}
\hline No. & Species & Collection site & & Accession No. \\
\hline 1 & Lefua sp. 2 & YahagiB4 & Aichi, Yahagi R. & LC062792 \\
\hline 2 & & YahagiB5 & Aichi, Yahagi R. & LC062793 \\
\hline 3 & & YahagiB6 & Aichi, Yahagi R. & LC062794 \\
\hline 4 & & YahagiB7 & Aichi, Yahagi R. & LC062795 \\
\hline 5 & & YahagiC2 & Aichi, Yahagi R. & LC062796 \\
\hline 6 & & YahagiD1 & Aichi, Yahagi R. & LC062797 \\
\hline 7 & & YahagiE3 & Aichi, Yahagi R. & LC062798 \\
\hline 8 & & YahagiF1 & Aichi, Yahagi R. & LC062799 \\
\hline 9 & & YahagiG0 & Aichi, Yahagi R. & LC062800 \\
\hline 10 & & YahagiG1 & Aichi, Yahagi R. & LC062801 \\
\hline 11 & & YahagiG8 & Aichi, Yahagi R. & LC062802 \\
\hline 12 & & YahagiG9 & Aichi, Yahagi R. & LC062803 \\
\hline 13 & & YahagiI1 & Aichi, Yahagi R. & LC062804 \\
\hline 14 & & Yahagil & Aichi, Yahagi R. & ${ }^{*} \mathrm{AB} 251875$ \\
\hline 15 & & Yahagi2 & Aichi, Yahagi R. & ${ }^{*} \mathrm{AB} 251877$ \\
\hline 16 & & Yahagi3 & Aichi, Yahagi R. & LC062805 \\
\hline 17 & & Yahagi4 & Aichi, Yahagi R. & LC062806 \\
\hline 18 & & Yahagi5 & Aichi, Yahagi R. & LC062807 \\
\hline 19 & & YahagiF0 & Aichi, Yahagi R. & LC062808 \\
\hline 20 & & Yahagi2012 & Aichi, Yahagi R. & LC062809 \\
\hline 21 & & Yahagigawa & Aichi, Yahagi R. & LC062810 \\
\hline 22 & & Nishikiriyamagawa & Aichi, Yahagi R. & LC062852 \\
\hline 23 & & Mitogawa & Aichi, Mito R. & LC062811 \\
\hline 24 & & Nisidagawa & Aichi, Nisida R. & LC062851 \\
\hline 25 & & OtowagawaA1 & Aichi, Otowa R. & LC062812 \\
\hline 26 & & OtowagawaA2 & Aichi, Otowa R. & LC062813 \\
\hline 27 & & OtowagawaA3 & Aichi, Otowa R. & LC062814 \\
\hline 28 & & OtowagawaA4 & Aichi, Otowa R. & LC062815 \\
\hline 29 & & OtowagawaA5 & Aichi, Otowa R. & LC062816 \\
\hline 30 & & OtowagawaB1 & Aichi, Otowa R. & LC062817 \\
\hline 31 & & OtowagawaB2 & Aichi, Otowa R. & LC062818 \\
\hline 32 & & OtowagawaB3 & Aichi, Otowa R. & LC062819 \\
\hline 33 & & OtowagawaB4 & Aichi, Otowa R. & LC062820 \\
\hline 34 & & OtowagawaB5 & Aichi, Otowa R. & LC062821 \\
\hline 35 & & OtowagawaC1 & Aichi, Otowa R. & LC062822 \\
\hline 36 & & OtowagawaC2 & Aichi, Otowa R. & LC062823 \\
\hline 37 & & OtowagawaC3 & Aichi, Otowa R. & LC062824 \\
\hline 38 & & OtowagawaC4 & Aichi, Otowa R. & LC062825 \\
\hline 39 & & OtowagawaC5 & Aichi, Otowa R. & LC062826 \\
\hline 40 & & Yamazakigawa1 & Aichi, Otowa R. & LC062827 \\
\hline
\end{tabular}




\section{Continued}

\begin{tabular}{|c|c|c|c|}
\hline 41 & Yamazakigawa2 & Aichi, Otowa R. & LC062828 \\
\hline 42 & Yamazakigawa3 & Aichi, Otowa R. & LC062829 \\
\hline 43 & Yamazakigawa4 & Aichi, Otowa R. & LC062830 \\
\hline 44 & Yamazakigawa5 & Aichi, Otowa R. & LC062831 \\
\hline 45 & Shitara2 & Aichi, Toyo R. & LC062832 \\
\hline 46 & Shitara6 & Aichi, Toyo R. & ${ }^{\star} \mathrm{AB} 251872$ \\
\hline 47 & Shitara8 & Aichi, Toyo R. & ${ }^{\star A B} 251873$ \\
\hline 48 & Shitara21 & Aichi, Toyo R. & ${ }^{\star A B} 251874$ \\
\hline 49 & Shitara25 & Aichi, Toyo R. & LC062833 \\
\hline 50 & Shitara26 & Aichi, Toyo R. & ${ }^{*} \mathrm{AB} 251876$ \\
\hline 51 & Shimoshimada & Aichi, Toyo R. & LC062834 \\
\hline 52 & Motoyagawa & Aichi, Toyo R. & ${ }^{\star A B} 599766$ \\
\hline 53 & Ichinosegawa & Aichi, Toyo R. & LC062839 \\
\hline 54 & Bunyagawa & Aichi, Toyo R. & LC062840 \\
\hline 55 & Takaragawa & Aichi, Toyo R. & LC062841 \\
\hline 56 & Aigou & Aichi, Toyo R. & LC062842 \\
\hline 57 & Soezawaonsen & Aichi, Toyo R. & LC062843 \\
\hline 58 & Tadamochi & Aichi, Toyo R. & LC062844 \\
\hline 59 & Tugegawa & Aichi, Toyo R. & LC062845 \\
\hline 60 & Houraiji & Aichi, Toyo R. & LC062846 \\
\hline 61 & Hourai & Aichi, Toyo R. & ${ }^{\star A B} 251871$ \\
\hline 62 & Marukomesawa & Aichi, Toyo R. & LC062847 \\
\hline 63 & Takise & Aichi, Toyo R. & LC062848 \\
\hline 64 & Wakamiyajinja & Aichi, Toyo R. & LC062849 \\
\hline 65 & Aderagawa & Aichi, Toyo R. & LC062850 \\
\hline 66 & Shimada & Aichi, Toyo R. & LC062853 \\
\hline 67 & Uregawa & Aichi, Toyo R. & LC062854 \\
\hline 68 & Ozawagawa & Aichi, Toyo R. & LC062855 \\
\hline 69 & Sanagawa & Aichi, Sana R. & ${ }^{*} \mathrm{AB} 599767$ \\
\hline 70 & Gotengawa & Aichi, Tenryu R. & ${ }^{\star A B} 251870$ \\
\hline 71 & Takihashigawa & Aichi, Tenryu R. & LC062835 \\
\hline 72 & Fukayagawa & Aichi, Tenryu R. & LC062836 \\
\hline 73 & Nanegawa & Aichi, Tenryu R. & LC062838 \\
\hline 74 & Nagaishigawa & Shizuoka, Tenryu R. & LC062837 \\
\hline 75 & Kaminobegawa & Shizuoka, Tenryu R. & LC062856 \\
\hline 76 & Mikkabichouhonmachi & Shizuoka, Miyakoda R. & LC062858 \\
\hline 77 & Oota & Shizuoka, Miyakoda R. & ${ }^{* * A B 599770}$ \\
\hline 78 & Santou & Shizuoka, Miyakoda R. & LC062859 \\
\hline 79 & Kougataihei & Shizuoka, Miyakoda R. & ${ }^{* *} \mathrm{AB} 599768$ \\
\hline 80 & Kosai & Shizuoka, Miyakoda R. & ${ }^{\star} \mathrm{AB} 251878$ \\
\hline
\end{tabular}




\section{Continued}

\begin{tabular}{|c|c|c|c|c|}
\hline 81 & & Fumagawa & Shizuoka, Oota R. & LC062857 \\
\hline 82 & & Kanzagawa & Shizuoka, Oota R. & LC062860 \\
\hline 83 & & Morimachiichimiya & Shizuoka, Oota R. & ${ }^{* *}$ AB599769 \\
\hline 84 & Lefua echigonia & Atsumi & Aichi & ${ }^{*} \mathrm{AB} 102846$ \\
\hline 85 & & Iwafuzigawa & Aichi & LC062861 \\
\hline 86 & & Usukogawa & Aichi & LC062862 \\
\hline 87 & & Ooshiro & Aichi & LC062863 \\
\hline 88 & & Kairikegawa & Aichi & LC062864 \\
\hline 89 & & Shirotorigawa & Aichi & LC062865 \\
\hline 90 & & Shinshiro & Aichi & ${ }^{*} \mathrm{AB} 102845$ \\
\hline 91 & & Damine-1A & Aichi & LC062867 \\
\hline 92 & & Damine-1B & Aichi & LC062868 \\
\hline 93 & & Damine-2 & Aichi & LC062869 \\
\hline 94 & & Donodagawa & Aichi & LC062870 \\
\hline 95 & & Tomoegawa & Aichi & LC062871 \\
\hline 96 & & Harakawa & Aichi & LC062872 \\
\hline 97 & & Miyashitagawa & Aichi & LC062874 \\
\hline 98 & & Yanamisawa & Aichi & LC062875 \\
\hline 99 & & Sizenkansatsunomori & Aichi & LC062876 \\
\hline 100 & & Norisadagawa & Aichi & LC062877 \\
\hline 101 & & Hirayabugawa & Aichi & LC062878 \\
\hline 102 & & Torakumagawa & Aichi & LC062879 \\
\hline 103 & & Ikedagawa & Aichi & LC062880 \\
\hline 104 & & Otowagawa & Aichi & LC062881 \\
\hline 105 & & Hagurigawa & Aichi & LC062882 \\
\hline 106 & & Terashimogawa & Aichi & LC062883 \\
\hline 107 & & Kazikawa & Aichi & LC062884 \\
\hline 108 & & Mitogawa & Aichi & LC062885 \\
\hline 109 & & Miyagawa & Aichi & LC062873 \\
\hline 110 & & Suyahara & Aichi & LC062866 \\
\hline 111 & & Sanagawa & Aichi & LC062886 \\
\hline 112 & & Shouzinngawa & Aichi & LC062891 \\
\hline 113 & & Shizuoka & Shizuoka & *AB599746 \\
\hline 114 & & Sagara & Shizuoka & ${ }^{\star} \mathrm{AB} 251866$ \\
\hline 115 & & Ishioka & Shizuoka & LC062887 \\
\hline 116 & & Ono & Shizuoka & LC062888 \\
\hline 117 & & Kakegawa & Shizuoka & ${ }^{\star} \mathrm{AB} 177699$ \\
\hline 118 & & Kosai & Shizuoka & ${ }^{*} \mathrm{AB} 102844$ \\
\hline 119 & & Seirigawa & Shizuoka & LC062889 \\
\hline 120 & & Morimachiookubo & Shizuoka & LC062890 \\
\hline 121 & & Gifu & Gifu & ${ }^{*} \mathrm{AB} 102843$ \\
\hline 122 & & Seki & Gifu & LC062892 \\
\hline 123 & & Ise & Mie & ${ }^{\star} \mathrm{AB} 102849$ \\
\hline 124 & Lefua sp.1 & Hidaka & Wakayama & ${ }^{*} \mathrm{AB} 177672$ \\
\hline 125 & Lefua echigonia & Aogaki & Hyogo & ${ }^{\star} \mathrm{AB} 102850$ \\
\hline 126 & Lefua echigonia & Ouchi & Akita & ${ }^{*} \mathrm{AB} 177677$ \\
\hline
\end{tabular}

${ }^{\star}$ Deposited previously; ${ }^{* *}$ Deposited previously and revised in this study. 


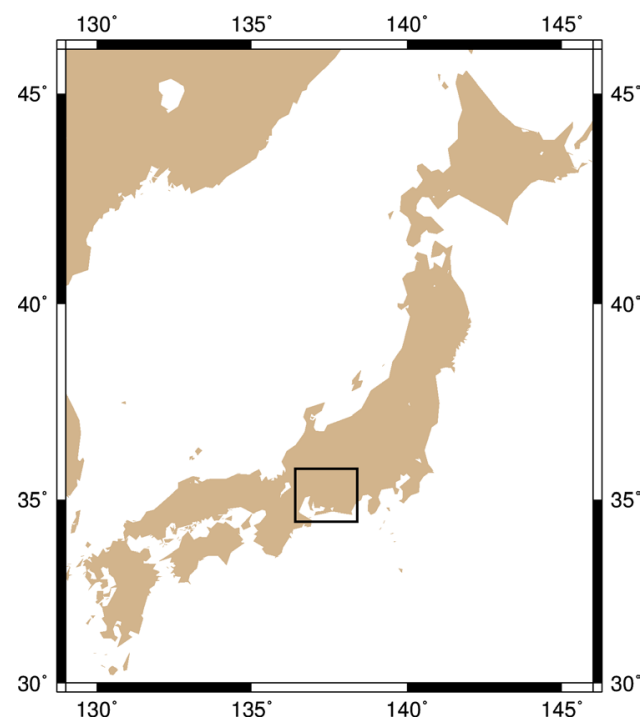

(a)

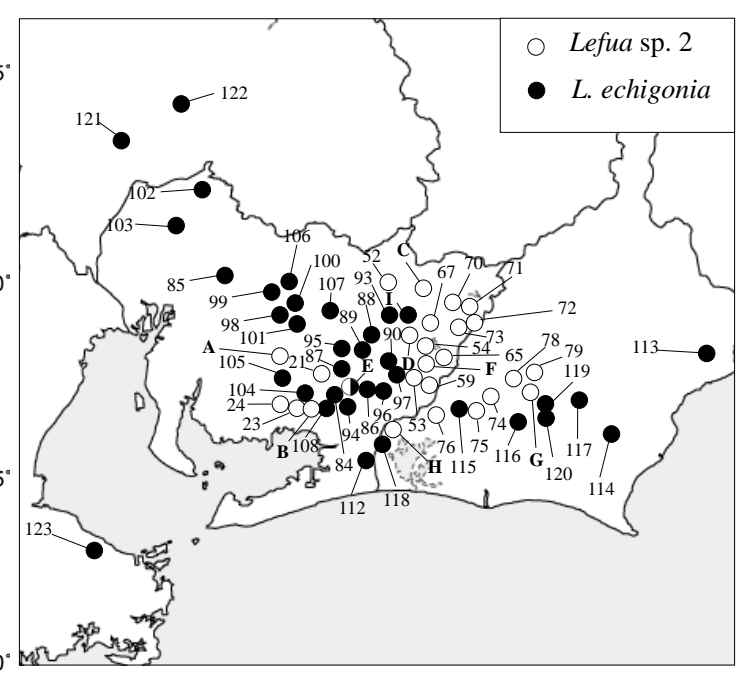

(b)

Figure 1. Locations in the Tokai region where specimens of Lefua sp. 2 and L. echigonia were collected Refer to Table 1 for details of the collection sites and sample numbers. We used large white circles for sample localities of Lefua sp. 2 and large black circles for those of L. echigonia. As a result, each circle does not always represent a single locality and in some cases integrated pleural localities. The numbers accompanied with circles denote the sample numbers in Table 1. A to I accompanied with circles include the following samples; A, 1-20; B, 22, 25-44; C, 45-50, 55, 57, 63; D, 51, 56, 58, 61, 66, 68; E, 69, 109 , 110,$111 ; \mathrm{F}, 60,62,64 ; \mathrm{G}, 80,82 ; \mathrm{H}, 77,81,83 ; \mathrm{I}, 91,92$.

\subsection{DNA Sequencing}

Total DNA from fin or muscle of each fish was prepared using a DNeasy ${ }^{\oplus}$ Blood \& Tissue Kit (QIAGEN GmbH, Hilden) according to the manufacturer's protocol. To amplify mtDNA containing the D-loop region, PCR was performed in a reaction solution $(50 \mu \mathrm{l})$ containing template DNA $(2 \mu \mathrm{l})$ and KOD dash (Toyobo Co., Ltd., Osaka) with an initial denaturation at $94^{\circ} \mathrm{C}$ for $2 \mathrm{~min}$, followed by 30 cycles of denaturation at $94^{\circ} \mathrm{C}$ for $30 \mathrm{sec}$, annealing at $55^{\circ} \mathrm{C}$ for $10 \mathrm{sec}$, and extension at $74^{\circ} \mathrm{C}$ for $30 \mathrm{sec}$, and with final extension at $74^{\circ} \mathrm{C}$ for $7 \mathrm{~min}$. Sequences of the primers used for amplification are shown in Table 2 [7]. The amplified DNA fragment was purified using a QIAquick Purification Kit (QIAGEN $\mathrm{GmbH}$, Hilden). Direct sequencing of the double-stranded PCR product was performed using an ABI PRISM BigDye Terminator v1.1 Cycle Sequencing Kit (Applied Biosystems Inc., California) and the primers used for PCR on Model 377 and 377XL DNA sequencers (Applied Biosystems) according to the manufacturer's directions. Alternatively, direct sequencing was performed using a Genome Lab $^{\text {mi }}$ DTCS-Quick Start Kit on a CEQ ${ }^{\text {mo }}$ 2000XL DNA Analysis system (Beckman Coulter Inc., California) according to the manufacturer's directions.

New sequence data were deposited in the DDBJ database under accession numbers LC062792-062892. We had previously determined mtDNA sequences used in this study (AB102843-102846, AB102849, AB102850, AB177672, AB177677, AB177699, AB251866, AB251870-251878, AB599746, AB599766599770 [1] [6] [7] [16]). 
Table 2. Primers used in this study.

\begin{tabular}{ccc}
\hline Sense & ProS & 5'GCATCGGTCTTGTAATCCGAAGAT3' \\
& $296 \mathrm{~S}$ & 5'ATATATTAATGTAGTAAGAAACCACCAACCAG3' \\
& $651 \mathrm{~S}$ & 5'TCAACACATCCTTATACTATATGC3' \\
Antisense & $334 \mathrm{AS}$ & 5'ATATATCACCTTCCACTTATGTCCC3' \\
& 194AS & 5'ACATTAATACTCGTTAATTTTATTGCGCTC3' \\
& PheAS & 5'GGACCAAGCCTTTGTGCATGCGGAG3' \\
\hline
\end{tabular}

\subsection{Phylogenetic Analysis}

DNA sequences of the mitochondrial D-loop region were edited and aligned using DNASIS (Hitachi Software Engineering Co., Ltd., Tokyo) and MEGA 6.0 [18], and the alignments were corrected by visual inspection. We used $825 \mathrm{bp}$ for the Lefua sp. 2 phylogeny and 867 bp for the L. echigonia phylogeny in the Tokai region, excluding indels and ambiguous sites. Neighbor-joining (NJ) and maximum parsimony (MP) trees were constructed using MEGA 6.0 and PAUP ${ }^{\star} 4.0$ beta10 [19], respectively. Genetic distances were computed by Kimura's twoparameter model [20]. Tree reliability was evaluated by generating 1,000 bootstrap replicates. The majority-rule consensus MP tree was constructed by conducting a heuristic search based on the 1,000 bootstrap replicates with an unweighted ts/tv ratio. The Bayesian (BA) tree was constructed using MrBayes version 3.1.2 [21] based on the model evaluated by the MrModeltest 2.3 [22]. The best models were GTR $+\mathrm{I}+\mathrm{G}$ for the Lefua sp. 2 phylogeny and HKY $+\mathrm{G}$ for the L. echigonia phylogeny. The Monte Carlo Markov chain (MCMC) length was $5 \times 10^{6}$ generations, and we sampled the chain every 100 generations. MCMC convergence was assessed by calculating the potential scale reduction factor, and the first $1 \times 10^{4}$ generations were discarded. The minimum spanning tree representing relationships among haplotypes was constructed using MEGA 6.0 and haplotype and nucleotide diversities and Genetic differentiation ( Fst) were calculated using Arlequin 3.5.1.2 [23]. The statistical significance of $F$ st was evaluated by calculating $1 \times 10^{4}$ values.

\section{Results}

1) Phylogenic relationships in Lefua sp. 2 and L. echigonia from the Tokai region

To determine phylogenetic relationships of 83 specimens in Lefua sp. 2, the NJ tree was constructed based on 825-bp sequences using Lefua sp. 1 from Hidaka and $L$. echigonia from Ouchi as the outgroup (Figure 2). There were 58 variable sites and 29 parsimony informative sites. Most branches were very short, indicating high sequence similarities. The monophyly of Lefua sp. 2 was well supported (NJ, 100; MP, 100; BA, 1.00), but other groupings within Lefua sp. 2 were generally not well supported because of high sequence similarities. We arbitrarily designated assemblies including specimens mainly from Yahagi, Toyo, and Tenryu River systems as Groups 1 to 3, respectively. Group 1 comprised specimens collected in the major Yahagi and neighboring minor Mito, Nishida, and 


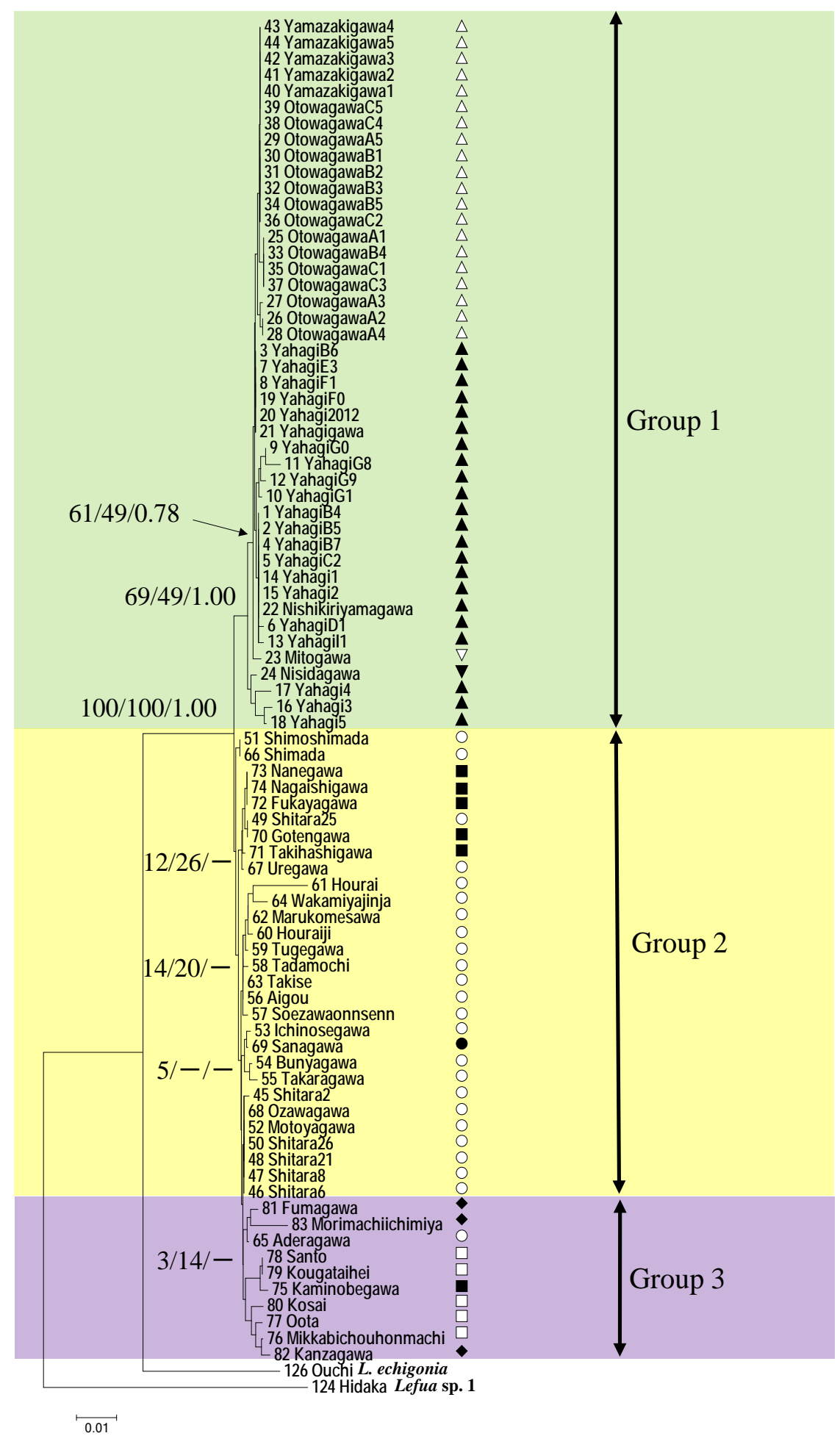

Figure 2. Phylogenetic relationships in Lefua sp. 2 based on the 825-bp mitochondrial D-loop sequences. The NJ tree was constructed based on genetic distances calculated with Kimura's two-parameter model using a total of 85 samples including Lefua sp. 1 from Hidaka and L. echigonia from Ouchi as the outgroup. The scale bar indicates 0.01 substitutions per site. Statistical supports of tree topologies are specified with NJ (left) and MP (middle) bootstrap values and BA posterior probabilities (right) in the vicinity of corresponding nodes. Simbols denote river systems: $\boldsymbol{\Lambda}$, Yahagi; $\nabla$, Mito; $\boldsymbol{\nabla}$, Nishida; $\triangle$, Otowa; $\bigcirc$, Toyo; , Oota. 
Otowa River systems (hereafter abbreviated as the Yahagi River system), and was marginally supported (NJ, 69; MP, 49; BA, 1.00). Group 2 was consisted of specimens collected in the major Toyo and neighboring minor Sana River systems (hereafter abbreviated as the Toyo River system), and was paraphyletic to Group 3. Group 3 comprised specimens collected in the major Tenryu and neighboring minor Miyakoda and Oota River systems (hereafter abbreviated as the Tenryu River system), and was poorly supported (NJ, 3; MP, 14; BA, -). Group $2+$ Group 3 is monophyletic, albeit poorly supported. Group 2 included exceptionally five specimens collected in the Tenryu River system. As described in the Discussion, localities of those specimens from the Tenryu River system, Gotengawa, Takihashigawa, Fukayagawa, Nanegawa, and Nagaishigawa (sample Nos. 70-74 in Table 1), are very close to tributaries of the Toyo River system. Group 3 included an exceptional specimen from the Toyo River system (Aderagawa, sample No. 65).

The p-distance and Fst were low between Groups 2 and 3, although those between Groups 1 and 2 and between Groups 1 and 3 were relatively higher (Table 3), suggesting that Lefua sp. 2 in the Yahagi River system was moderately differentiated from that in the other river systems. MP and BA trees demonstrated similar basal divergences, but splitting at the tip was not conservatively recovered (data not shown).

To determine phylogenetic relationships of 40 specimens in L. echigonia, the NJ tree was constructed based on 867-bp sequences using L. echigonia from Aogaki and Ouchi as the outgroup (Figure 3). There were 105 variable sites and 26 parsimony informative sites. The monophyly of specimens from the Tokai region, i.e. the Tokai population of L. echigonia, was well supported (NJ, 95; MP, 97; BA, 0.99). We arbitrarily designated assemblies as Groups A and B. Group A comprised specimens from Shizuoka and southeastern Aichi prefectures (NJ, 41; MP, -; BA, 0.90) and Group B from northwestern Aichi, Gifu, and Mie prefectures (NJ, 47; MP, 56; BA, 0.61). The p-distance and Fst between Groups A and $B$ were low, but their $\mathrm{p}$-distance was higher than those within each group (Table 4). MP and BA trees demonstrated similar basal divergences, but splitting at the tip was not conservatively recovered (data not shown).

2) Haplotype relationships in Lefua sp. 2 and L. echigonia from the Tokai region

Forty-five haplotypes were detected in Lefua sp. 2, and the minimum spanning tree was constructed to represent their relationships (Figure 4). The tree showed a complicated network of haplotypes, but haplotypes represented by

Table 3. Genetic divergence in Lefua sp. 2.

\begin{tabular}{llll}
\hline & Group 1 & Group 2 & Group 3 \\
\hline Group 1 & 0.00314 & $0.64271^{\star}$ & $0.65775^{\star}$ \\
Group 2 & 0.01046 & 0.00408 & $0.22491^{\star}$ \\
Group 3 & 0.01412 & 0.00767 & 0.00854 \\
\hline
\end{tabular}

Above diagonal, Fst; on diagonal, intragroup p-distance; below diagonal, intergroup p-distance. ${ }^{*}$ statistically significant $(P<0.05)$. 


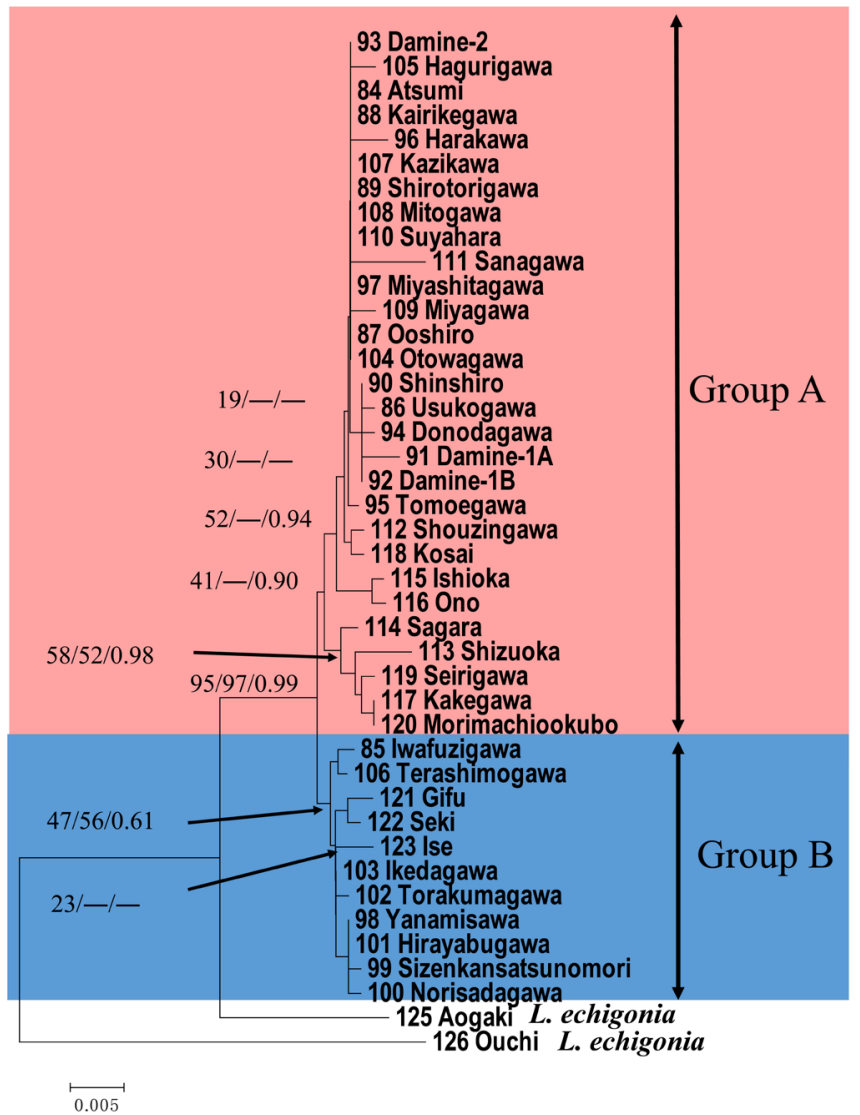

Figure 3. Phylogenetic relationships in L. echigonia based on the 867-bp mitochondrial D-loop sequences The NJ tree was constructed based on genetic distances calculated with Kimura's two-parameter model using a total of 42 samples including L. echigonia from Aogaki and Ouchi as the outgroup. The scale bar indicates 0.005 substitutions per site. Statistical supports of tree topologies are specified with NJ (left) and MP (middle) bootstrap values and BA posterior probabilities (right) in the vicinity of corresponding nodes.

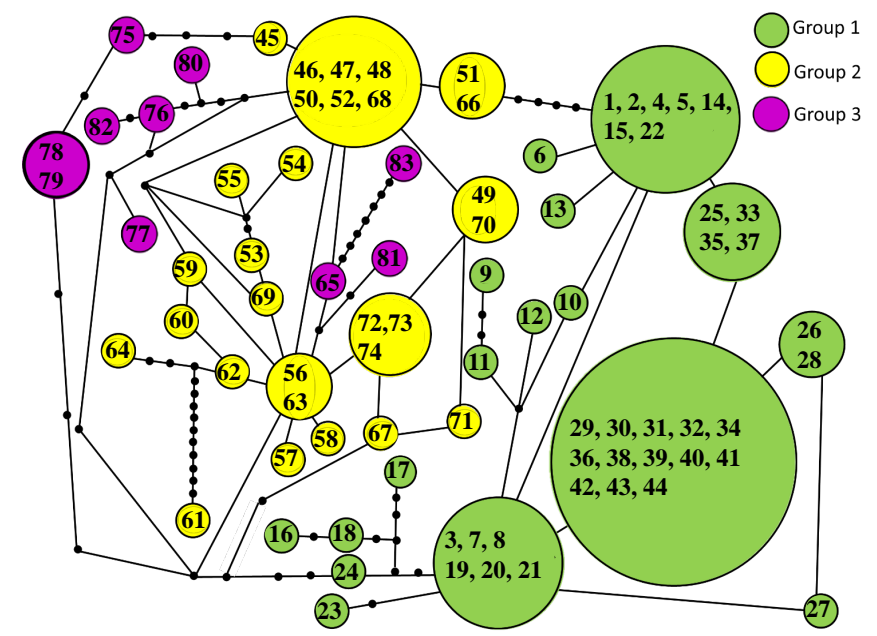

Figure 4. Minimum spanning tree of 45 haplotypes in Lefua sp. 2 Circles indicate haplotypes and their dimensions are proportional to the number of individuals possessing the same haplotype. Black circles on lines indicate hypothetical haplotypes not found in this study. The numbers denote the sample numbers in Table 1. Dark grey (purple in the color version), Group 3; pale grey (yellow), Group 2; intermediate grey (green), Group 1. 
Table 4. Genetic divergence in L. echigonia.

\begin{tabular}{ccc}
\hline & Group A & Group B \\
\hline Group A & 0.005068 & $0.44564^{*}$ \\
Group B & 0.008262 & 0.003649 \\
\hline
\end{tabular}

Above diagonal, $F$ st; on diagonal, intragroup p-distance; below diagonal, intergroup p-distance; ${ }^{*}$, statistically significant $(P<0.05)$.

specimens belonging to the three groups were roughly separated from one another. The haplotypes of those belonging to the Yahagi River system were relatively well separated from the others, supporting that Lefua sp. 2 in the Yahagi River system was genetically differentiated from the others. The haplotypes of Gotengawa, Takihashigawa, Fukayagawa, Nanegawa, and Nagaishigawa from the Tenryu River system were included in the assembly of haplotypes from the Toyo River system, while those of Aderagawa, Fumagawa (sample No. 81), and Morimachiichimiya (83) from Group 3 were included in the assembly of haplotypes from Group 2. Therefore, Lefua sp. 2 in the Toyo River system was not genetically distinguishable well from that in the Tenryu River system.

Twenty-eight haplotypes were detected in L. echigonia, and the minimum spanning tree was constructed to represent their relationships (Figure 5). A star-like structure of haplotype relationships was represented with the haplotype of the greatest majority shared by 10 specimens from eastern Aichi prefecture.

3) Haplotype and nucleotide diversities in Lefua sp. 2 and L. echigonia from the Tokai region

Values of the haplotype diversity in Lefua sp.2 were relatively high and similar between groups (Table 5), but values of the nucleotide diversity were very low and those in Groups 1 and 2 (Yahagi and Toyo River systems) were lower than that in Group 3 (Tenryu River system). High haplotype and low nucleotide diversities in L. echigonia were similar between Groups A and B.

\section{Discussion}

Our results showed that Lefua sp. 2 was an established entity in the Lefua loaches (see also [7] [15]), and that there were not well-defined genetic structures discernible within Lefua sp. 2. Taking the D-loop as the fastest evolving region in mitochondrial DNA into account, Lefua sp. 2 dispersed quite recently, or it has been maintained as a single population for long time. Lefua sp. 2 is more closely related to L. echigonia than to Lefua sp. 1. Divergence of Lefua sp. 2 and $L$. echigonia was estimated at $1.4-1.5$ million years ago, whereas that of the Tokai and Kinki populations of L. echigonia at 0.7 million years ago [1] [7]. Despite its long history, Lefua sp. 2 represented low intraspecific genetic distances (Table 3) and low nucleotide diversity, although haplotype diversity was relatively high because a number of haplotypes with small nucleotide changes were detected (Table 5). Therefore, Lefua sp. 2 might have once reduced its population size and dispersed recently from the relic area(s), which is not the case when its 


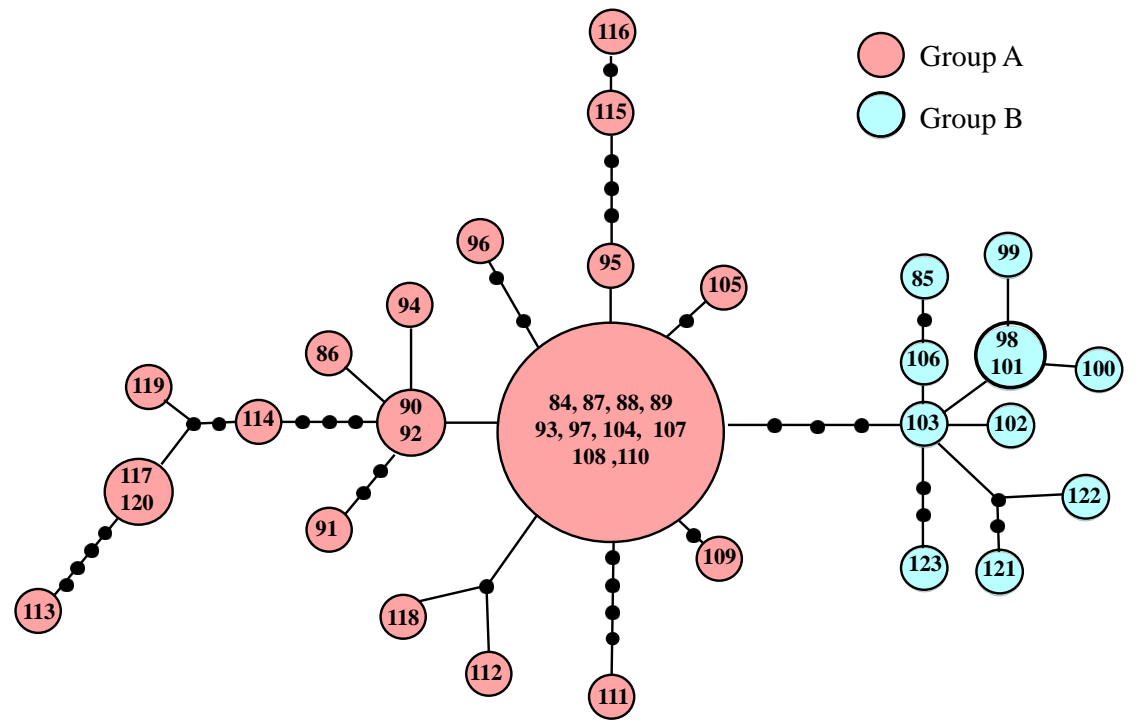

Figure 5. Minimum spanning tree of 28 haplotypes in L. echigonia Circles indicate haplotypes and their dimensions are proportional to the number of individuals possessing the same haplotype. Black circles on lines indicate hypothetical haplotypes not found in this study. The numbers denote the sample numbers in Table 1. Dark grey (pink in the color version), Group A; pale grey (blue), Group B.

Table 5. Haplotype and nucleotide diversities in Lefua sp. 2 and L. echigonia.

\begin{tabular}{llcl}
\hline & $\mathrm{n}$ & Haplotype diversity & Nucleotide diversity \\
\hline Group 1 & 44 & $0.8721 \pm 0.0340$ & $0.003135 \pm 0.001901$ \\
Group 2 & 25 & $0.9444 \pm 0.0295$ & $0.004082 \pm 0.002401$ \\
Group 3 & 14 & $0.9778 \pm 0.0540$ & $0.008539 \pm 0.004956$ \\
Group A & 29 & $0.8783 \pm 0.0595$ & $0.005178 \pm 0.002926$ \\
Group B & 11 & $0.9818 \pm 0.0463$ & $0.003649 \pm 0.002305$ \\
\hline
\end{tabular}

n, number of samples.

evolutionary rate has been extremely slow. However, specimens from the Yahagi River system were moderately differentiated from those from the Toyo and Tenryu River systems, although it is difficult to distinguish definitely specimens between the Toyo and Tenryu River systems. Thus, we can consider that Lefua sp. 2 consists of two natural populations, that is, the Yahagi River population and the Toyo-Tenryu River population.

Star-like relationships of haplotypes in L. echigonia suggested the dispersal origin located in eastern Aichi prefecture. This does not look consistent with our assumption that $L$. echigonia invaded the Tokai region from the western habitat, near the boundary between the distributional ranges of the Tokai and Kinki populations. The invasion was caused by erosion of the western flanking zone of MLT and the development of relatively flat terrain more suitable for L. echigonia than for Lefua sp. 2. However, it is possible that the dispersal origin of the former western habitat has already been lost, possibly because of destruction by human activities. 
In Lefua sp. 2, the specimens from Gotengawa, Takihashigawa, Fukayagawa, Nanegawa, and Nagaishigawa in the northwestern Tenryu River system were more closely related to those in the Toyo River system than to those in the southeastern Tenryu River system. The distance between tributaries of the northwestern Tenryu River and northeastern Toyo River is less than $1.5 \mathrm{~km}$. Therefore, we assumed that Lefua sp. 2 was introduced from the Toyo River to Tenryu River by river capturing. This provides a biological clue in resolving whether river capturing between the Tenryu and Toyo Rivers occurred previously. River capturing has been suggested based on river trajectories, while Ikeda [24] insisted from research of riverine sediments that there was no river capturing between the two rivers. The present study indicated that at least a northeastern part of the Toyo River was captured by a northwestern part of the Tenryu River. The specimen from Aderagawa in the Toyo River system was exceptionally included in Group 3. The collection site of Aderagawa is very close to the tributary of Tenryu River. This also suggests river capturing between the Toyo and Tenryu Rivers, although we cannot eliminate the possibility of artificial transplantation of Lefua sp. 2 from the Tenryu River to Toyo River. Nevertheless, the present results suggest that the Toyo River and Tenryu River systems form a single population through gene flow facilitated by river capturing. Population genetic studies of various taxa can present more solid information of geological settings such as river capturing in the Tokai region.

The two populations should be considered as evolutionary significant units (ESUs) for the conservation of Lefua sp. 2. The translocation of fishes is severely prohibited by a guideline issued by the Ichthyological Society of Japan; however, there are some problems to follow this guideline. One of them is how to define ESUs. We consider it important to regard a natural population as an ESU. Many fish habitats have been fragmented by anthropogenic activities. Especially for fishes inhabiting montane streams, such as Lefua sp. 2, dam and weirs construction is critical by preventing fishes from returning upstream to their original habitats when they are displaced downstream by strong currents after heavy rains. Individuals are often isolated from each other and divided into small assemblages, and thus a natural population is destroyed by the obstruction of gene flow. Small assemblages are susceptible to bottlenecking, and haplotypes included in an original population can be fixed in different manners in different tributaries. When assemblages are investigated using genetic makers, they can be recognized as genetically distinct and thus reasoned to be assigned to different ESUs. However, they are small anthropogenic populations, but not natural populations. In this case, translocation is prohibited based on anthropogenic but not natural grounds. Next is how finely ESUs should be defined. We still have genetic markers separating organisms up to the individual level, and thus we can define ESUs more finely using faster-evolving genetic markers. However, it is very difficult or impossible and even impractical to conserve so many finely defined ESUs. We have to resolve these problems to adopt the best procedure for the fish conservation. Specimens of L. echigonia from the Tokai region showed lower genetic dif- 
ferences between Group A and B (0.008 in Table 4) than those of Lefua sp. 2 between Group 1 and Group 2 or 3 (over 0.010 in Table 3). Presently we cannot say whether two groups of $L$. echigonia can be regarded as ESUs.

Many Japanese freshwater fishes are facing to extinction. Urgent measures appropriate to each fish species are indispensable to protect them and guide lines are needed to be further refined. The present study contributes to protection of endangered eight-barbel loaches by giving fundamental genetic information and defining new ESUs in Lefua sp. 2. Studies such as the present study are crucial and will together lead to comprehensive conservation of Japanese freshwater fishes in future.

\section{Acknowledgements}

We express our sincere thanks to Mr. Michikazu Matsuda, Mr. Masayoshi Sugiura, Dr Seiichi Mori, Dr. Kazumi Hosoya, Mr. Tesuo Kamei, Mrs. Yumiko Yamashina, Mrs. Keiko Muraoka, Mr. Osamu Inaba, Mr. Koichi Kirihara, and Mr. Sakae Nakamura for their assistance in collecting loaches and for providing useful information on the biology of Lefua loaches.

\section{References}

[1] Mihara, M., Sakai, T., Nakao, K., Martins, L. de O., Hosoya, K. and Miyazaki, J.-I. (2005) Phylogeography of Loaches of the Genus Lefua (Balitoridae, Cypriniformes) Inferred from Mitochondrial DNA Sequences. Zoological Science, 22, 157-168. https://doi.org/10.2108/zsj.22.157

[2] Shedko, S.V., Miroshnichenko, I.L. and Nemkova, G.A. (2008) On the Systematics and Phylogeography of Eight-Barbel Loaches of the Genus Lefua (Cobitoidea: Nemacheilidae) mtDNA Typing of L. pleskei. Russian Journal of Genetics, 44, 817-825. https://doi.org/10.1134/S1022795408070090

[3] Hosoya, K. (1994) Lefua echigonia. In: The Fisheries Agency, Ed., Basic Data on Threatened Wild Aquatic Organism in Japan-I, The Fisheries Agency, Tokyo, 386391. (In Japanese)

[4] Hosoya, K. (2014) Lefua echigonia and Lefua sp. 1. In: Ministry of the Environment, Ed., Red Data Book 2014-Threatened Wildlife of Japan-, Gyosei Corporation, Tokyo, 196-199. (In Japanese)

[5] Yamashina, Y., Kamei, T. and Hosoya, K. (1994) Preliminary Report on Two Lefua Species Obtained from Hikami District. Hyogo Freshwater Biology, 45, 5-11. (In Japanese)

[6] Miyazaki, J.-I., Nakao, K., Mihara, M., Sakai, T., Gunji, Y., Tojo, K., Muraoka, K. and Hosoya, K. (2007) Incongruence between mtDNA Phylogeny and Morphological and Ecological Characters in Loaches of the Genus Lefua (Balitoridae, Cypriniformes). Zoological Science, 24, 666-675. https://doi.org/10.2108/zsj.24.666

[7] Miyazaki, J.-I., Dobashi, M., Tamura, T., Beppu, S., Sakai, T., Mihara, M. and Hosoya, K. (2011) Parallel Evolution in Eight-Barbel Loaches of the Genus Lefua (Balitoridae, Cypriniformes) Revealed by Mitochondrial and Nuclear DNA Phylogenies. Molecular Phylogenetics and Evolution, 60, 416-427. https://doi.org/10.1016/j.ympev.2011.05.005

[8] Hosoya, K. (2013) Cobitidae. In: Nakabo, T., Ed., Fishes of Japan with Pictorial Keys to the Species, 3rd Edition, Tokai University Press, Hadano, 328-334, 1819-1822. (In 
Japanese)

[9] Okada, Y. and Seiishi, R. (1938) Studies on the Early Life History of Nine Species of Fresh-Water Fishes. Bulletin of the Biogeographical Society of Japan, 8, 223-253.

[10] Miyadi, D., Kawanabe, H. and Mizuno, N. (1976) Lefua echigonia. In: Colored Illustrations of the Freshwater Fishes of Japan, Hoikusha, Osaka, 254-256. (In Japanese)

[11] Hosoya, K. (1988) Lefua echigonia Jordan et Richardson. In: Okiyama, M., Ed., An Atlas of the Early Stage Fishes in Japan, Tokai University Press, Tokyo, 272-276.

[12] Aoyama, S. and Doi, T. (2011) Morphological Comparison of Early Stages of Two Japanese Species of Eight-Barbel Loaches: Lefua echigonia and Lefua sp. (Nemacheilidae). Folia Zoologica, 60, 355-361.

[13] Kuwahara, T. (2014) L. nikkonis. In: Ministry of the Environment, Ed., Red Data Book 2014- Threatened Wildlife of Japan-, Gyosei Corporation, Tokyo, 194-195. (In Japanese)

[14] Miyazaki, J.-I. (2014) Lefua sp. 2. In: Ministry of the Environment, Ed., Red Data Book 2014- Threatened Wildlife of Japan-, Gyosei Corporation, Tokyo, 200-201. (In Japanese)

[15] Sano, I., Kirikane, M., Ogata, K., Kobayshi, K., Tojo, K. and Miyazaki, J.-I. (2016) Phylogeny in Eight-Barbel Loaches of the Genus Lefua (Balitoridae, Cypriniformes) Based on Nucleotide Sequences of the Mitochondrial Cytochrome $b$ Gene. Bulletin of the Faculty of Education (University Yamanashi), 1, 183-192. (In Japanese)

[16] Sakai, T., Mihara, M., Shitara, H., Yonekawa, H., Hosoya, K. and Miyazaki, J.-I. (2003) Phylogenetic Relationships and Intraspecific Variations of Loaches of the Genus Lefua (Balitoridae, Cypriniformes). Zoological Science, 20, 501-514. https://doi.org/10.2108/zsj.20.501

[17] Moritz, C. (1994) Defining "Evolutionarily Significant Units" for Conservation. Trends in Ecology \& Evolution, 9, 373-375. https://doi.org/10.1016/0169-5347(94)90057-4

[18] Tamura, K., Stecher, G., Peterson, D., Filipski, A. and Kumar, S. (2013) MEGA6: Molecular Evolutionary Genetics Analysis Version 6.0. Molecular Biology and Evolution, 30, 2725-2729. https://doi.org/10.1093/molbev/mst197

[19] Swofford, D.L. (2002) PAUP*: Phylogenetic Analysis Using Parsimony (and Other Methods), Version 4.0 Beta 10. Sinauer Associates, Sunderland.

[20] Kimura, M. (1980) A Simple Method for Estimating Evolutionary Rates of Base Substitutions through Comparative Studies of Nucleotide Sequences. Journal of Molecular Evolution, 16, 111-120. https://doi.org/10.1007/BF01731581

[21] Huelsenbeck, J.P., Ronquist, F., Nielsen, R. and Bollback, J.P. (2003) Bayesian Inference of Phylogeny and Its Impact on Evolutionary Biology. Science, 294, 2310-2314. https://doi.org/10.1126/science.1065889

[22] Posada, D. and Buckley, T.R. (2004) Model Selection and Model Averaging in Phylogenetics: Advantages of the AIC and Bayesian Approaches over Likelihood Ratio Tests. Systematic Biology, 53, 793-808. https://doi.org/10.1080/10635150490522304

[23] Excoffier, L. and Lischer, H.E.L. (2010) Arlequin Suite Ver 3.5: A New Series of Programs to Perform Population Genetics Analyses under Linux and Windows. Molecular Ecology Resources, 10, 564-567. https://doi.org/10.1111/j.1755-0998.2010.02847.x

[24] Ikeda, Y. (1971) Kasen No Soudatu To Teni. Kenkyu Kiyou of Aichi Prefectural Education Center, 45, 107-136. (In Japanese) 
Submit or recommend next manuscript to SCIRP and we will provide best service for you:

Accepting pre-submission inquiries through Email, Facebook, LinkedIn, Twitter, etc. A wide selection of journals (inclusive of 9 subjects, more than 200 journals)

Providing 24-hour high-quality service

User-friendly online submission system

Fair and swift peer-review system

Efficient typesetting and proofreading procedure

Display of the result of downloads and visits, as well as the number of cited articles Maximum dissemination of your research work

Submit your manuscript at: http://papersubmission.scirp.org/

Or contact jwarp@scirp.org 